\title{
Vaginal Birth After Cesarean in California: Before and After a Change in Guidelines
}

\author{
Jobn Zweifler, MD, MPH \\ Alvaro Garza, MD, $M P H^{2}$ \\ Susan Hughes, $M S^{1}$ \\ Matthew A Stanich, MPH \\ Anne Hierbolzer ${ }^{3}$ \\ Monica Lau \\ 'Department of Family and Community \\ Medicine, University of California, San \\ Francisco, Fresno, Calif \\ ${ }^{2}$ Latino Center for Medical Education and \\ Research, University of California, San \\ Francisco, Fresno, Calif \\ ${ }^{3}$ Summer Biomedical Research Internship \\ Program, University of California, San \\ Francisco, Fresno, Calif
}

\begin{abstract}
PURPOSE In 1999 the American College of Obstetricians and Gynecologists (ACOG) adopted more-restrictive guidelines for vaginal birth after cesarean delivery (VBAC). This study assesses trends in VBAC in California and compares neonatal and maternal mortality rates among women attempting VBAC delivery or undergoing repeat cesarean delivery before and after this guideline revision.
\end{abstract}

METHODS The 1996 through 2002 California Birth Statistical Master Files were used to identify 386,232 California residents who previously gave birth by cesarean delivery and had a singleton birth planned in a California hospital.

RESULTS Attempted VBAC deliveries decreased significantly from $24 \%$ before to $13.5 \%$ after guideline revision $(P<.001)$. Neonatal mortality rates per 1,000 live births for attempted VBAC deliveries were not different from repeat cesarean delivery rates among neonates weighing $\geq 1,500 \mathrm{~g}$ in either the study periods 1996 to 1999 or 2000 to 2002. Neonatal mortality rates for attempted VBAC deliveries were higher for repeat cesarean deliveries among neonates weighing $<1,500 \mathrm{~g}$ in the same periods (attempted VBAC: 1996-1999, 253.2; 95\% Poisson confidence interval [Cl], 197.7-308.6; 2000-2002, 336.8; Cl, 254.3-419.4; repeat cesarean delivery: 1996-1999, 59.1; Cl, 48.3-69.9; 2000-2002, 60.5, Cl, 48.472.5). Maternal death rates per 100,000 live births for attempted VBAC deliveries were similar for both periods (1996-1999, 2.0; Cl, 0.1-11.0; 2000-2002, 8.5; Cl, 1.0-30.6).

CONCLUSIONS Neonatal and maternal mortality rates did not improve despite increasing rates of repeat cesarean delivery during the years after the ACOG 1999 VBAC guideline revision. Women with infants weighing $\geq 1,500$ g encountered similar neonatal and maternal mortality rates with VBAC or repeat cesarean delivery.

Ann Fam Med 2006:4:228-234. DOI: 10.1370/afm.544

\section{INTRODUCTION}

The percentage of babies born by cesarean section increased in the United States from $4.5 \%$ in 1965 to $26.1 \%$ in $2002 .{ }^{1,2}$ Nearly $40 \%$ of cesarean sections are repeats. ${ }^{2}$ Federal reports in the 1980 s and 1990s promoted vaginal birth after cesarean section (VBAC) as a safe and reasonable alternative. ${ }^{3,4}$ In 1994 and 1995 the American College of Obstetricians and Gynecologists (ACOG) stated, "A woman with one previous cesarean delivery with a lower uterine segment incision should be counseled and encouraged [italics added] to undergo a trial of labor in her current pregnancy." ${ }^{15,6}$ Safety issues and medicolegal considerations, however, appear to have contributed to ACOG subsequently adopting more restrictive recommendations regarding VBAC deliveries. ${ }^{7,8}$ In 1999, the ACOG revised position became, "... because uterine rupture may be catastrophic, VBAC should be attempted in institutions equipped to respond to emergencies with physicians immediately available [italics added] to provide emergency care. ${ }^{18}$ Meanwhile, VBAC rates climbed from $1 \%$ in 1974 , to $27.4 \%$ in 1997 before declining to $12 \%$ in $2002 . .^{2,9}$

The recommendation that VBAC deliveries should be attempted only 
in institutions equipped to respond to emergencies with physicians immediately available could have a greater impact on VBAC deliveries at rural hospitals, where there may be less access to physician and emergency services. The 2004 reaffirmation by ACOG of its VBAC guidelines ${ }^{10}$ has been challenged by the American Academy of Family Physicians Policy on Trial of Labor After Cesarean (TOLAC). ${ }^{11}$ Although observational studies conducted in years before 1999 found VBAC deliveries in rural and smaller hospitals to be safe, ${ }^{12-14}$ studies of VBAC deliveries and adverse birth outcomes before and after the ACOG 1999 VBAC guideline revision are still needed.

Our study addresses the following questions: Did the appraoch to VBAC deliveries change after the 1999 guideline revision? Did rates of VBAC change similarly at rural and urban hospitals during this time? Did rates of neonatal and maternal mortality for births among women with previous cesarean sections differ between 1996-1999 and 2000-2002 or between delivery methods? To answer these questions, we analyzed California birth data from 1996-2002 and compared neonatal and maternal mortality in years before and after the ACOG 1999 VBAC guideline revision.

\section{METHODS}

Birth data were obtained from the California Department of Health Services Birth Statistical Master Files for the years 1996 through 2002. The variables used for analyses included maternal demographics, birthspecific measures, and hospital designation as rural or urban. Maternal demographics included age, race, ethnicity, education, and California county of residence. Birth measures abstracted from the Birth Statistical Master File were date of birth, date of newborn death, type of birth (singleton or multiple), birth weight, method of delivery, pregnancy complications, delivery complications, hospital code, planned birthplace (hospital, birth center, residence, or unplanned), and California county of birth. The University of California, San Francisco, Institutional Review Board approved this study as exempt.

Rural hospital names were identified according to the California Office of Statewide Health Planning and Development designation of "small/rural hospital."15 Because we noted that 4 hospitals were not consistently designated, hospitals ever designated as rural in this time frame were considered rural for our study. Hospitals not matching the rural list were considered urban.

The State of California Certificate of Live BirthVS-10A Medical Data Supplemental Work Sheet defined all the codes used to document complications of pregnancy. We created a composite variable for pregnancy complications that took into consideration all reported complications. ${ }^{16}$ Although birth certificates categorized electronic fetal monitoring and ultrasound examinations as pregnancy complications, we did not include them as pregnancy complications. If any pregnancy complication besides "none" or electronic fetal monitoring or ultrasound examination was coded, the composite variable for that record was categorized as having a pregnancy complication.

Data were analyzed using SAS (Version 8.2; SAS Institute Inc, Cary, NC). We considered records of all California residents with a singleton birth planned in a California hospital and then created a subset of women who had had a previous cesarean section. Certificate of Live Birth information was used to categorize the delivery method as either attempted VBAC, successful or failed (including other delivery assistance), or repeat cesarean delivery. Method of delivery options on the Certificate of Live Birth included "cesarean section-repeat" and "vaginal birth-after previous cesarean section" (successful VBAC). The Certificate of Live Birth codes "unsuccessful attempt at vaginal birth after cesarean section" as a delivery complication. This code was used to identify a failed VBAC. We summed the successful and failed VBAC deliveriess to derive the numbers of attempted VBAC deliveries. "Maternal death (within 72 hours of delivery)," also coded as a delivery complication, was used to define maternal death, although the standard World Health Organization (WHO) definition of maternal death is within 42 days. We calculated neonatal deaths using the standard WHO definition of newborns living for less than 28 days. The neonatal morbidity-hypoxicischemic encephalopathy-and the maternal morbidity-uterine rupture-are not included as Certificate of Live Birth codes and were therefore not part of this analysis. Newborn very low birth weight was defined as less than $1,500 \mathrm{~g}$, low birth weight as 1,500 to 2,499 $\mathrm{g}$, normal birth weight as 2,500 to $4,000 \mathrm{~g}$, and large birth weight as more than $4,000 \mathrm{~g}$.

We calculated percentages of women who attempted VBAC deliveries within categories of maternal demographics for 2 time spans: 1996 to 1999, before the ACOG VBAC guideline revision; and 2000 to 2002, after the ACOG VBAC guideline revision. $\mathrm{A} \chi^{2}$ test was used to examine the difference in VBAC attempts in the 2 periods. Neonatal death rates were calculated per 1,000 live births with 95\% Poisson confidence intervals (CI). ${ }^{17}$ Neonatal death rates were then stratified by delivery method, birth weight category, and the period before or after the guideline revision. A power calculation, at $80 \%$ power and $5 \%$ significance level, based on our sample size of neonates weighing more than 2,500 $\mathrm{g}$ indicated that we would be able 
to detect a difference of 0.1023 deaths per 1,000 live births between the categories of repeat cesarean section and attempted VBAC. Multiple logistic regression was used to test whether neonatal death rates differed by location of hospital (rural or urban), study period, delivery method, pregnancy complications, or birth weight category. Maternal death rates with confidence intervals were calculated per 100,000 live births by study period and delivery method.
RESULTS

Demographics of Vaginal Births After Cesarean (VBAC)

There were more than 3.5 million singletons delivered to California residents at California hospitals during our study time span, 1996-2002 (Figure 1). Of those births, $10.9 \%(386,232)$ were to women with previous cesarean sections, which comprised our sample. The VBAC rate (VBAC among women with previous cesar-

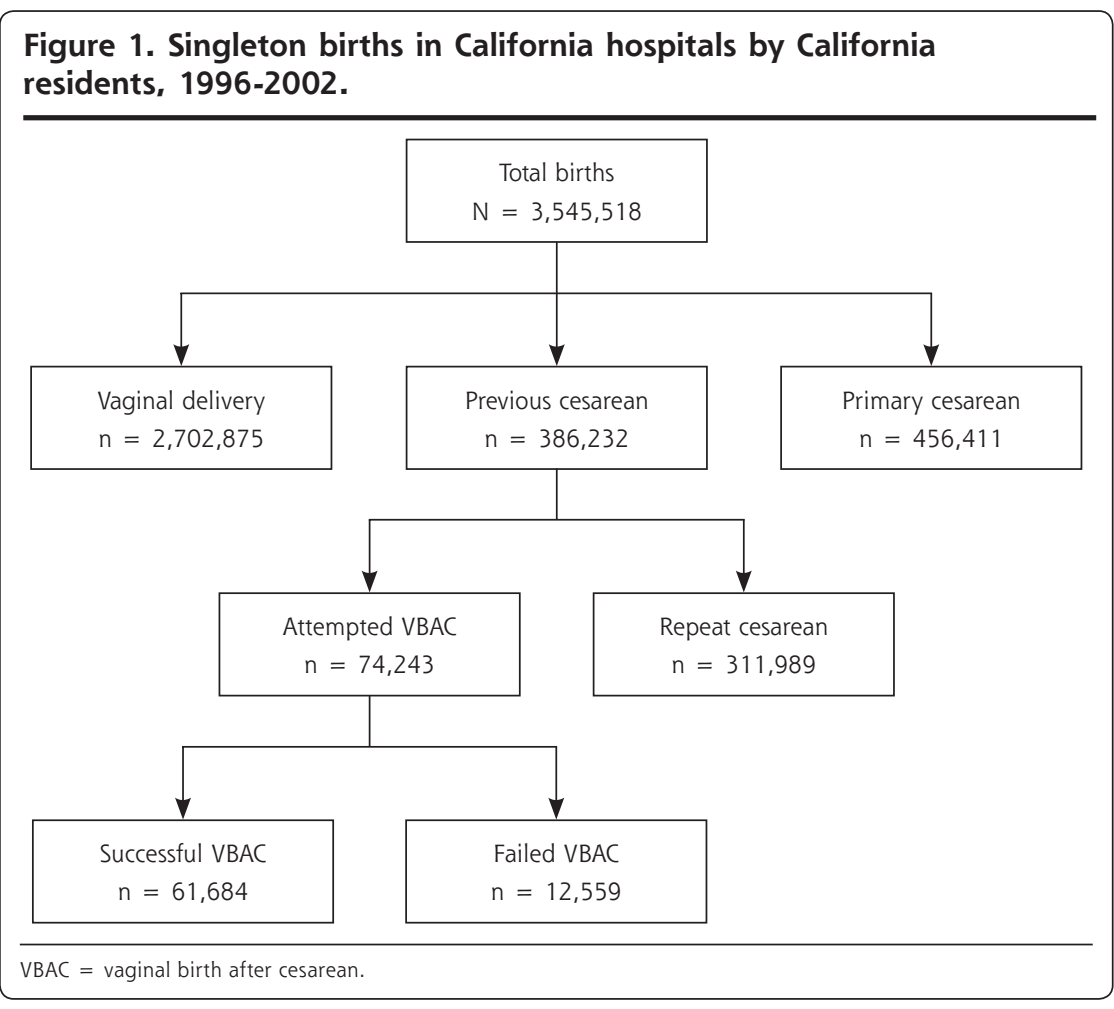

Figure 2. Successful vaginal births in women with previous cesarean section delivery: California, 1996-2002.

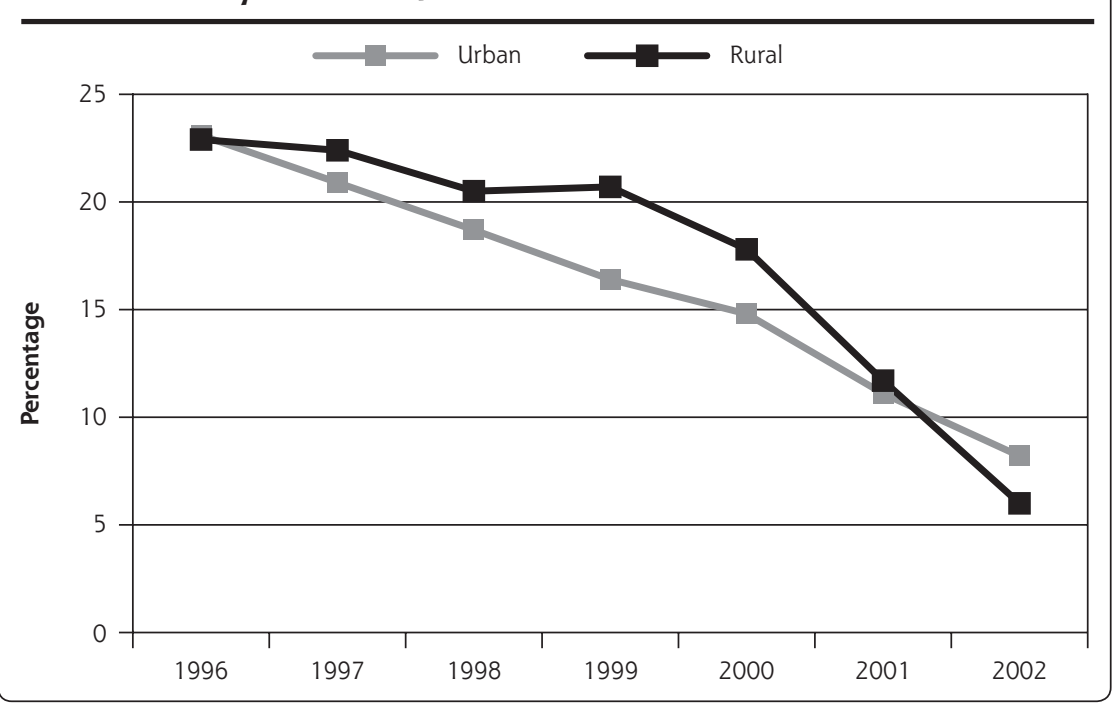

ean sections) was $16 \%$, and

the success rate of attempted VBAC deliveries was $79.5 \%$ in rural and $83.3 \%$ in urban settings (data not shown). Overall, $3.9 \%(138,275)$ of all births in California occurred at rural hospitals, and $4.5 \%(17,380)$ of all previous cesarean section births were rural. Rural and urban differences in the decline of VBAC over the years were not significant and, although VBAC deliveries declined more rapidly at rural hospitals after 1999, the decline started at least as early as 1997 (Figure 2).

Table 1 displays by maternal demographic characteristics the percentage of women with a previous cesarean delivery $(386,232)$ who attempted vaginal birth. Overall, the percentage of women who attempted VBAC deliveries decreased significantly from $24 \%$ before the revision to $13.5 \%$ after the revision $(P<.001)$. The percentage of decrease in attempted VBAC between the 2 periods was less in older mothers, in black mothers, and in those with pregnancy complications. Overall, recorded pregnancy complications were higher in women who attempted VBAC than in those who had a repeat cesarean section in both before the revision and after the revision periods, as were specific complications including diabetes, premature labor, preeclampsia, anemia, or polyhydramnios/oligohydramnios (data not shown). The rate 


\begin{tabular}{|c|c|c|c|}
\hline \multirow{2}{*}{$\begin{array}{l}\text { Maternal } \\
\text { Characteristics }\end{array}$} & \multicolumn{2}{|c|}{ Attempt VBAC (\%) } & \multirow{2}{*}{$\begin{array}{c}\text { Decrease } \\
(\%)\end{array}$} \\
\hline & $1996-1999$ & $2000-2002$ & \\
\hline Overall* & 24.0 & 13.5 & 44 \\
\hline \multicolumn{4}{|l|}{ Age, years* } \\
\hline$<20$ & 26.6 & 11.7 & 56 \\
\hline $20-29$ & 25.2 & 13.9 & 45 \\
\hline $30-39$ & 23.3 & 13.4 & 42 \\
\hline $40-49$ & 19.3 & 11.2 & 42 \\
\hline \multicolumn{4}{|l|}{ Race/ethnicity* } \\
\hline White & 25.6 & 14.0 & 45 \\
\hline Hispanic & 22.6 & 12.6 & 44 \\
\hline Black & 21.6 & 14.3 & 34 \\
\hline Asian & 29.5 & 17.5 & 41 \\
\hline Other & 25.6 & 14.7 & 43 \\
\hline \multicolumn{4}{|l|}{ Education* } \\
\hline Less than high school & 22.6 & 12.4 & 45 \\
\hline High school & 23.3 & 13.1 & 44 \\
\hline Some college & 25.2 & 14.5 & 42 \\
\hline College degree & 27.2 & 15.2 & 44 \\
\hline \multicolumn{4}{|l|}{ Hospital status* } \\
\hline Rural & 27.3 & 14.8 & 46 \\
\hline Urban & 23.8 & 13.4 & 44 \\
\hline \multicolumn{4}{|l|}{ Pregnancy complication* } \\
\hline Yes & 28.1 & 18.0 & 36 \\
\hline No & 22.8 & 12.5 & 45 \\
\hline
\end{tabular}

of attempted VBAC in both periods was positively associated with education level.

\section{Neonatal and Maternal Deaths}

Table 2 displays neonatal mortality rates per 1,000 live births among women with a previous cesarean delivery by birth weight category, delivery method, and the period before and after the revision. Neonatal mortality rates for attempted VBAC deliveries were not different from those for repeat cesarean deliveries, except among neonates of very low birth weight in both periods (highlighted in table). Neonatal mortality rates for failed VBAC deliveries were not significantly different from rates for successful VBAC or repeat cesarean deliveries, except for a higher rate in the after-revision normal-birth-weight category (highlighted in table). The proportion with successful VBAC was inversely related to birth weight (very low birth weight $92.9 \%$, low birth weight $87.6 \%$, normal birth weight $84.3 \%$, and large birth weight $73.4 \%$; data not shown).

Among all births, multiple logistic regression analysis showed the strongest predictor of neonatal death to be very low birth weight (Table 3). There was no sig-

Table 2. Neonatal Death Rates by Birth Weight, Delivery Method, and Study Period, California, 1996-2002

\begin{tabular}{|c|c|c|c|c|c|c|c|c|c|}
\hline \multirow[b]{3}{*}{$\begin{array}{l}\text { Delivery } \\
\text { Method }\end{array}$} & \multirow[b]{3}{*}{$\begin{array}{l}\text { Study } \\
\text { Period }\end{array}$} & \multicolumn{8}{|c|}{ Neonatal Deaths per 1,000 Live Births } \\
\hline & & \multicolumn{2}{|c|}{$<1,500 \mathrm{~g}$} & \multicolumn{2}{|c|}{$1,500-2,499 \mathrm{~g}$} & \multicolumn{2}{|c|}{$2,500-4,000 \mathrm{~g}$} & \multicolumn{2}{|c|}{$>4,000 \mathrm{~g}$} \\
\hline & & $\mathrm{n}^{*}$ & $\begin{array}{c}\text { Rate } \\
\left(95 \% \mathrm{Cl}^{+}\right) \\
\end{array}$ & n & $\begin{array}{c}\text { Rate } \\
\left(95 \% \mathrm{Cl}^{+}\right)\end{array}$ & $\mathrm{n}$ & $\begin{array}{c}\text { Rate } \\
\left(95 \% \mathrm{Cl}^{\dagger}\right)\end{array}$ & $\mathrm{n}$ & $\begin{array}{c}\text { Rate } \\
\left(95 \% \mathrm{Cl}^{\dagger}\right)\end{array}$ \\
\hline \multirow[t]{2}{*}{$\begin{array}{l}\text { Attempted } \\
\text { VBAC }\end{array}$} & 1996-1999 & 316 & $\begin{array}{c}253.2 \\
(197.7-308.6)\end{array}$ & 1,589 & $1.8(0.4-5.5)$ & 42,248 & $0.3(0.2-0.5)$ & 6,517 & $0.3(0.0-1.1)$ \\
\hline & $2000-2002$ & 190 & $\begin{array}{c}336.8 \\
(254.3-419.4)\end{array}$ & 838 & $7.2(2.6-15.6)$ & 19,682 & $0.4(0.1-0.7)$ & 2,863 & $0.0(0.0-1.3)$ \\
\hline \multirow[t]{2}{*}{$\begin{array}{l}\text { Successful } \\
\text { VBAC }\end{array}$} & 1996-1999 & 292 & $\begin{array}{c}267.1 \\
(207.8-326.4)\end{array}$ & 1,387 & $2.2(0.4-6.3)$ & 35,528 & $0.3(0.2-0.6)$ & 4,754 & $0.0(0.0-0.8)$ \\
\hline & $2000-2002$ & 178 & $\begin{array}{c}359.6 \\
(271.5-447.6)\end{array}$ & 738 & $8.1(3.0-17.7)$ & 16,672 & $0.1(0.0-0.4)$ & 2,135 & $0.0(0.0-1.7)$ \\
\hline \multirow[t]{2}{*}{ Failed VBAC } & 1996-1999 & 24 & $\begin{array}{c}83.3 \\
(10.1-301.0)\end{array}$ & 202 & $0.0(0.0-18.3)$ & 6,720 & $0.3(0.0-1.1)$ & 1,763 & $1.1(0.1-4.1)$ \\
\hline & $2000-2002$ & 12 & $\begin{array}{c}0.0 \\
(0.0-307.5)\end{array}$ & 100 & $0.0(0.0-36.9)$ & 3,010 & $1.7(0.5-3.9)$ & 728 & $0.0(0.0-5.1)$ \\
\hline \multirow[t]{2}{*}{ Repeat CS } & 1996-1999 & 1,947 & $\begin{array}{c}59.1 \\
(48.3-69.9)\end{array}$ & 6,407 & $4.7(3.3-6.7)$ & 128,417 & $0.4(0.3-0.5)$ & 23,559 & $0.1(0.0-0.4)$ \\
\hline & $2000-2002$ & 1,604 & $\begin{array}{c}60.5 \\
(48.4-72.5)\end{array}$ & 6,072 & $6.9(5.0-9.3)$ & 124,224 & $0.3(0.2-0.4)$ & 19,462 & $0.5(0.3-0.9)$ \\
\hline \multicolumn{10}{|c|}{$\begin{array}{l}\text { Note: Neonatal death rates calculated for singleton births delivered in California hospitals by California residents with a previous cesarean delivery, 1996-2002. } \\
\text { Numbers bolded show significant differences (Cls do not overlap) within the birth weight category. }\end{array}$} \\
\hline \multicolumn{10}{|c|}{$\begin{array}{l}\mathrm{Cl}=\text { confidence interval; } \mathrm{VBAC}=\text { vaginal birth after cesarean; attempted } \mathrm{VBAC}=\text { successful } \mathrm{VBAC}+\text { failed } \mathrm{VBAC} ; \mathrm{CS}=\text { cesarean section. } \\
\text { * Total number of births in each category. } \\
\text { † } 95 \% \text { Poisson Cls. }\end{array}$} \\
\hline
\end{tabular}


nificant association between neonatal death and delivery method in a rural hospital, and a slightly protective association with the period before the revision, ie, the odds of death were higher in the period after the revision. These associations did not change when only newborns weighing $<2,500$ g were analyzed. Finally, in a regression analysis including only newborns of normal and large birth weight, pregnancy complication was the only significant predictor of neonatal mortality (OR, 3.1; CI, 2.2-4.5; data not shown).

During the 7 -year span of this study, only 35 maternal deaths occurred within 72 hours of delivery. Table 4 displays maternal death rates per 100,000 live births by delivery method and study period. For each delivery method, maternal death rates were not significantly different between the periods before and after the guideline revision. Maternal death rates for repeat cesarean section and attempted VBAC deliveries were also not significantly different.

\section{DISCUSSION}

We investigated VBAC delivery rates in California before and after the ACOG 1999 VBAC guideline revision that called for the immediate availability of cesarean section capability. We found that VBAC deliveries declined rapidly after 1999. This decline, however, seems to be the continuation of a trend that began in 1997 and mirrored national trends, perhaps reflecting unease among obstetricians and foreshadowing the 1999 revision. ${ }^{2,18,19}$ Our successful VBAC rate of $83 \%$ is higher than the $76 \%$ success rate found in a recent meta-analysis. ${ }^{11}$ The higher rate may reflect our inability to distinguish between planned and unplanned VBAC deliveries using birth certificate data.

We suspected that the more-stringent VBAC criteria established by ACOG would disproportionately affect rural hospitals, because rural obstetric clinicians presumably would have more difficulty being immediately available. ${ }^{20} \mathrm{VBAC}$ deliveries did decline faster in rural than in urban hospitals after 1999, although other factors, such as declining numbers of family physicians providing obstetric services or patient preferences, may have played a role.

We also investigated neonatal and maternal mortality in California before and after the ACOG guideline revision. California's neonatal and maternal mortality rates did not improve in the years after the 1999 revision, nor was rural hospital status a significant predictor of neonatal mortality. Although these findings do not support such a policy as ACOG's 1999 revision, which could be construed to especially discourage VBAC deliveries at rural hospitals, we cannot exclude the possibility that residual confounding by risk status
Table 3. Multiple Logistic Regression Analysis of the Association Between Delivery Characteristics and Neonatal Death in California from 1996-2002

\begin{tabular}{|c|c|c|}
\hline Characteristic & $\begin{array}{l}\text { Odds Ratio } \\
\left(95 \% \mathrm{Cl}^{*}\right)\end{array}$ & $P$ Value \\
\hline \multicolumn{3}{|l|}{ Date of delivery } \\
\hline $\begin{array}{l}\text { Post-ACOG revision, } \\
\text { 2000-2002 }\end{array}$ & 1.00 & - \\
\hline $\begin{array}{l}\text { Pre-ACOG revision, } \\
\text { 1996-1999 }\end{array}$ & $0.82(0.69-0.97)$ & .022 \\
\hline \multicolumn{3}{|l|}{ Birth weight } \\
\hline $2,500-4,000 \mathrm{~g}$ & 1.00 & - \\
\hline$<1,500 \mathrm{~g}$ & $273.61(215.70-347.07)$ & $<.001$ \\
\hline $1,500-2,499 \mathrm{~g}$ & $15.63(11.66-20.95)$ & $<.001$ \\
\hline$>4,000 \mathrm{~g}$ & $0.88(0.51-1.52)$ & .65 \\
\hline \multicolumn{3}{|l|}{ Delivery method } \\
\hline Repeat cesarean & 1.00 & - \\
\hline Attempted VBAC & $2.84(2.35-3.45)$ & $<.001$ \\
\hline Pregnancy complication ${ }^{\dagger}$ & $1.54(1.28-1.86)$ & $<.001$ \\
\hline \multicolumn{3}{|l|}{ Hospital location ${ }^{\ddagger}$} \\
\hline Urban & 1.00 & - \\
\hline Rural & $1.21(0.76-1.95)$ & .425 \\
\hline \multicolumn{3}{|c|}{$\begin{array}{l}\mathrm{Cl}=\text { confidence interval; } \mathrm{ACOG}=\text { American College of Obstetricians and } \\
\text { Gynecologists; } \mathrm{VBAC}=\text { vaginal birth after cesarean. }\end{array}$} \\
\hline \multicolumn{3}{|c|}{$\begin{array}{l}\text { * } 95 \% \text { Poisson Cl. } \\
\text { † Pregnancy complication is a composite variable based on codes noted in the } \\
\text { California Department of Health Services Certificate of Live Birth Medical Data } \\
\text { Supplemental Work Sheet, Item 29, and excludes mothers with electronic fetal } \\
\text { monitoring or ultrasound. }\end{array}$} \\
\hline \multicolumn{3}{|c|}{$\begin{array}{l}\text { f Hospital location based on California Office of Statewide Health Planning } \\
\text { and Development designation of "small/rural" during years 1996-2002. }\end{array}$} \\
\hline
\end{tabular}

Table 4. Maternal Deaths by Delivery Method and Study Period, California, 1996-2002

\begin{tabular}{lcc}
\hline & \multicolumn{2}{c}{$\begin{array}{c}\text { Maternal Death Rate } \\
\text { per 100,000 (95\% Cl*) }\end{array}$} \\
\cline { 2 - 3 } Delivery Method & $\mathbf{1 9 9 6 - 1 9 9 9}$ & $\mathbf{2 0 0 0 - 2 0 0 2}$ \\
\hline Attempted VBAC & $2.0(0.1-11.0)$ & $8.5(1.0-30.6)$ \\
Repeat cesarean & $8.7(4.8-14.6)$ & $11.9(7.0-18.8)$ \\
\hline Note: Maternal death within 72 hours of delivery; maternal death rates \\
calculated for singleton births delivered in California hospitals by California \\
residents with a previous cesarean. \\
Cl = confidence interval; VBAC = vaginal birth after cesarean. \\
* 95\% Poisson confidence interval.
\end{tabular}

might make rural hospitals compare more favorably. For example, rural pregnant women with high-risk conditions identified prenatally might preferentially select or be referred for delivery in urban settings better prepared to handle newborn complications. The finding that pregnancy complication for newborns $>2,500 \mathrm{~g}$ was the only significant predictor of neonatal mortality emphasizes the continuing need for detecting complications and referring when necessary.

Our finding of higher VBAC neonatal mortality rates confined to infants of very low birth weight is 
similar to that of a previous report. ${ }^{21}$ One possibility is that women with previous cesarean sections who have precipitous premature deliveries are classified as VBAC, even if they had planned to have a repeat cesarean section, which is supported by the higher rates of "successful" VBAC deliveries for infants of very low birth weight when compared with infants of other birth weights. Women who give birth precipitously have less time to receive antenatal steroids that improve neonatal mortality in infants of very low birth weight. ${ }^{22}$ Additionally, physicians and patients may be reluctant to subject pregnant women to an operative procedure if the newborn is unlikely to be viable. The finding that women with very low birth weight newborns who attempted a VBAC but ultimately had a cesarean section (failed VBAC) had similar neonatal mortality rates as women giving birth to very low birth weight infants by repeat cesarean section suggests the differences in neonatal mortality rates for infants of very low birth weight may be less a function of attempting a VBAC or electing to have a repeat cesarean section than a reflection of factors such as those described above.

This analysis reinforced important findings from previous studies of VBAC deliveries. No significant difference was found in maternal deaths for women who attempted a VBAC compared with those who had an elective repeat cesarean section. ${ }^{23-26} \mathrm{~A}$ much larger sample would be needed, however, to have the power to detect differences in maternal mortality. The proportion of older women and black women who attempted a VBAC delivery did not decrease after the 1999 revision to the same extent as the proportion of women from other age and racial/ethnic groups, a finding consistent with national VBAC trends. ${ }^{27}$

Our analysis of birth certificate information did not permit us to assess important neonatal or maternal morbidities, including neonatal hypoxic-ischemic encephalopathy or maternal uterine rupture. A recent prospective, nonblinded, multicenter observational study found higher rates of neonatal hypoxic-ischemic encephalopathy and maternal uterine rupture for women who underwent a trial of labor after cesarean (TOLAC) than women whose babies were delivered by repeat cesarean section. ${ }^{26}$ Our results agreed with those of Landon et al in finding no differences in neonatal mortality for term infants delivered by TOLAC or repeat cesarean section. Similarly, we both found no differences in maternal mortality, nor did Landon et al find higher rates of hysterectomy despite the higher rates of uterine rupture in their TOLAC group. ${ }^{26}$ Our study is not directly comparable with the Landon et al study, because there were differences in data collection methods (birth certificate analysis vs prospective chart review), population (State of California vs academic health centers), rates of successful VBAC (83\% vs $73 \%)$, and sample size $(311,989$ repeat cesarean deliveries with 74,243 attempted VBAC, compared with 15,801 repeat cesarean deliveries and 17,898 TOLAC). Landon et al included higher proportions of women who were younger than 30 years, black, and on government aid in their TOLAC group. Landon et al classified women who arrived dilated $4 \mathrm{~cm}$ or more in the TOLAC group, which could have selected for women at higher risk because of less compliance with labor and delivery instructions or limited prenatal care.

Our study was further limited by other factors. Our results depended on proper coding of birth certificates, which are subject to misclassification. ${ }^{28} \mathrm{We}$ were unable to determine whether there was underascertainment of VBAC or whether ascertainment occurred differently in patients with adverse outcomes. Birth certificate data are limited to what is routinely collected. Information not systematically collected includes gestational age or use of antenatal steroids, which are of particular importance in delivery outcomes for infants of very low birth weight. Birth certificate data of maternal mortality records only death within 72 hours, much less than the World Health Organization's standard definition of maternal death within 42 days. Finally, it might be difficult to generalize our results to populations outside California, since California births may occur in settings more or less ethnically diverse or rural than others, and the successful VBAC rate for all women with previous cesarean births in California in 2002 was $8.0 \%$, compared with the national rate of $12.6 \% .^{2}$ Even so, California's 528,000 births in 2002 constituted $13.1 \%$ of the $4,022,000$ US deliveries in that year. ${ }^{2}$

Our findings warrant further investigation. We recommend an assessment of the response of rural hospitals to the 1999 ACOG guideline revision, the capacity of rural hospitals to accommodate cesarean deliveries, and the risk status of mothers who give birth at rural or urban hospitals. We also recommend a study of neonatal mortality and morbidity associated with very low birth weight for women with previous cesarean sections that accounts for precipitous or unplanned VBAC deliveries.

During the last decade, the pendulum in the United States has swung dramatically away from VBAC deliveries and toward repeat cesarean section. ${ }^{29}$ The ACOG 1999 VBAC guideline revision reflects concern for VBAC delivery safety and may have accelerated this trend, particularly at rural hospitals. Our findings suggest that women expecting to give birth to normal- or large-birth-weight infants can anticipate similar neonatal mortality with a VBAC or a repeat cesarean section. These findings, based on 386,232 California births after 
previous cesarean delivery, do not contradict the AAFP TOLAC statement. Concerns, however, regarding medicolegal consequences of complications, such as uterine rupture, which we were unable to assess using birth certificate data, may continue to temper patient and physician enthusiasm for VBAC deliveries. We recommend that a balanced presentation of risks and the encouraging outcomes found in this analysis be included in discussions with pregnant patients who have had a previous cesarean section. An evidence-based approach to VBAC delivery incorporating these findings may lead to further refinements in guidelines for medically managing women with a previous cesarean delivery.

To read or post commentaries in response to this article, see it online at http://www.annfammed.org/cgi/content/full/4/3/228.

Key words: Vaginal birth after cesarean; infant mortality; obstetrics; rural health

Submitted August 10, 2005; submitted, revised, December 14, 2005; accepted December 26, 2005.

Portions of this manuscript were presented at the 38th Annual Spring Conference of the Society of Teachers of Family Medicine in New Orleans, La, May 2, 2005.

Acknowledgments: We wish to thank Norman Hearst, MD, MPH; Kathleen Ramos, PhD; and Sean Schafer, MD, for commenting on our manuscript.

\section{References}

1. Scott JR. Avoiding labor problems during vaginal birth after cesarean delivery. Clin Obstet Gynecol. 1997;40:533-541.

2. Martin JA, Hamilton BE, Sutton PD, et al. Births: final data for 2002. Natl Vital Stat Rep. 2003;52:1-113.

3. National Institutes of Health. Cesarean childbirth. NIH Consensus Statement Online. Available at: http://odp.od.nih.gov/consensus/ cons/027/027_statement.htm\#1. Accessed: 23 August 2004.

4. Healthy People 2000. Washington, DC: US Department of Health and Human Services; 1990.

5. Vaginal delivery after a previous cesarean birth. Washington, DC: American College of Obstetricians and Gynecologists. ACOG Committee on Obstetric Practice; 1994. Opinion No. 143.

6. ACOG Practice Patterns. Vaginal delivery after previous cesarean birth. Washington, DC: American College of Obstetricians and Gynecologists; 1995. Practice bulletin No. 1.

7. Flamm BL. Vaginal birth after cesarean: what's new in the new millennium? Curr Opin Obstet Gynecol. 2002;14:595-599.

8. Clinical management guidelines for obstetrician-gynecologists: vaginal birth after previous Cesarean delivery. Washington, DC: American College of Obstetricians and Gynecologists. ACOG Committee on Practice Bulletins; 1999. Practice Bulletin No. 5.
9. Harer WB, Jr. Vaginal birth after cesarean delivery: current status. JAMA. 2002;287:2627-2630.

10. ACOG Practice Bulletin \#54: vaginal birth after previous cesarean. Obstet Gynecol. 2004;104:203-212.

11. Wall E, Roberts R, Deutchman M, et al. Trial of Labor After Cesarean (TOLAC), Formerly Trial of Labor Versus Elective Repeat Cesarean Section for the Woman With a Previous Cesarean Section. Leawood, Kan: American Academy of Family Physicians; 2005.

12. Raynor BD. The experience with vaginal birth after cesarean delivery in a small rural community practice. Am J Obstet Gynecol. 1993;168:60-62.

13. Holland JG, Dupre AR, Blake PG, Martin RW, Martin JN, Jr. Trial of labor after cesarean delivery: experience in the non-university level II regional hospital setting. Obstet Gynecol. 1992;79:936-939.

14. Cameron B, Cameron S. Outcomes in rural obstetrics, Atherton Hospital 1991-2000. Aust J Rural Health. 2001;9(Suppl 1):S39-S42.

15. California Office of Statewide Health Planning and Development. Annual Hospital Utilization Pivot Profiles, 1999-2001. Available at: http://www.oshpd.state.ca.us/HQAD/HIRC/hospital/util/pivot/index. htm. Accessed: 10 October 2003.

16. California Department of Health Services Health and Welfare Agency. Certificate of Live Birth - VS-10A Medical Data Supplemental Work Sheet. Available at: http://www.avss.ucsb.edu/layouts/vs10a. htm. Accessed: 10 November 2003.

17. Armitage P, Berry G, Matthews JNS. Statistical Methods in Medical Research. 4th ed. Oxford: Blackwell Science Ltd; 2002.

18. Flamm BL. Once a cesarean, always a controversy. Obstet Gynecol. 1997:90:312-315

19. Vaginal birth after cesarean birth--California, 1996-2000. MMWR Morb Mortal Wkly Rep. 2002;51:996-998.

20. Pinette MG, Kahn J, Gross KL, et al. Vaginal birth after Cesarean rates are declining rapidly in the rural state of Maine. J Matern Fetal Neonatal Med. 2004;16:37-43.

21. Riva HL, Teich JC. Vaginal delivery after cesarean section. Am J Obstet Gynecol. 1961;81:501-510.

22. Effect of corticosteroids for fetal maturation on perinatal outcomes. NIH Consens Statement. 1994;12:1-24.

23. Socol ML. VBAC--is it worth the risk? Semin Perinatol. 2003;27:105111.

24. Smith GC, Pell JP, Dobbie R. Caesarean section and risk of unexplained stillbirth in subsequent pregnancy. Lancet. 2003;362:17791784.

25. Guise JM, Berlin M, McDonagh M, et al. Safety of vaginal birth after cesarean: a systematic review. Obstet Gynecol. 2004;103:420-429.

26. Landon MB, Hauth JC, Leveno KJ, et al. Maternal and perinatal outcomes associated with a trial of labor after prior cesarean delivery. N Engl J Med. 2004;351:2581-2589.

27. Menacker F, Curtin SC. Trends in cesarean birth and vaginal birth after previous cesarean, 1991-99. Natl Vital Stat Rep. 2001;49:1-16.

28. Green DC, Moore JM, Adams MM, et al. Are we underestimating rates of vaginal birth after previous cesarean birth? The validity of delivery methods from birth certificates. Am J Epidemiol. 1998; 147:581-586.

29. Grady D. Trying to avoid 2nd Caesarean, many find choice isn't theirs. New York Times. November 29, 2004: A1, A19. 